Página inicial: 419 - Página final: 445

TIPO DE ARTÍCULO: de Reflexión

\title{
SIGNIFICADOS EN TORNO A LA REPARACIÓN, LA AYUDA HUMANITARIA, LA INDEMNIZACIÓN Y LA RESTITUCIÓN EN VÍCTIMAS DEL CONFLICTO ARMADO EN EL MUNICIPIO DE SAN CARLOS. ${ }^{3}$
}

\author{
MEANINGS AROUND REPARATION, HUMANITARIAN ASSISTANCE, INDEMNIFICATION, AND RESTITUTION \\ IN VICTIMS OF THE ARMED CONFLICT IN THE MUNICIPALITY OF SAN CARLOS, ANTIOQUIA.
}

\author{
RECIBIDO: ENERO 2015 REVISADO: ABRIL 2015 CEPTADO: 2 DE MAYO DE 2015
}

Por: Juan David Villa Gómez ${ }^{1}$ y Alfonso Insuasty Rodriguez. ${ }^{2}$

\section{RESUMEN:}

Se presentan los primeros resultados de las indagaciones sobre la valoración que las mismas víctimas del conflicto armado, del municipio de San Carlos Antioquia (Colombia), hacen de la implementación de la Ley 1448 (Ley de Victimas); dicho proceso de investigación, en esta primera entrega, evidenció entre otros hallazgos, la contradicción entre el discurso oficial y el relato de las víctimas en relación a los procesos de reparación, discursos contradictorios respecto a la transición, el estado de vulneración e insatisfacción de necesidades básicas de las personas victimizadas así como una alta confusión en la implementación de la Ley. Estos resultados, entre otros, permiten afirmar que, la reparación hoy, dista mucho de ser un proceso que aporte a la reconstrucción del tejido social, a la paz y la reconciliación.

\section{PALABRAS CLAVE:}

Reparación, Víctimas, Conflicto armado, Justicia Transicional, reparación integral, ayuda humanitaria

\begin{abstract}
:
The first results of the inquiries on the valuation made by the very victims of the armed conflict, in the municipality of San Carlos Antioquia (Colombia) are shown in this paper, which are part of the implementation of the 1448 Law (Law of Victims); such a research process of, in this first installment, evidenced among other findings, the contradiction between the official discourse and the story of the victims in relation to the reparation processes, contradictory speeches regarding the transition, the state of infringement and dissatisfaction of victimized people's basic needs, as well as a high confusion as for the implementation of the Law. These findings, among others, allow to affirm that reparation today, is far from being a process that contributes to the reconstruction of the social fabric, to peace, and reconciliation.
\end{abstract}

\section{KEY WORDS:}

Reparation, victims, armed conflict, transitional justice, full reparation, humanitarian help.

\footnotetext{
${ }^{1}$ Psicólogo, Pontificia Universidad Javeriana (Bogotá - Colombia). Magister y PHD, Cooperación Internacional al Desarrollo Universidad Pontificia de Comillas (Madrid - España). Docente / Investigador Facultad de Psicología Universidad San Buenaventura (Medellín Colombia). Contacto: juand.villa@usbmed.edu.co

${ }^{2}$ Abogado, Licenciado en filosofía, Especialista en ciencias políticas y políticas públicas, Estudiante de doctorado en el Instituto para el Pensamiento y la Cultura en América Latina (Ipecal-México), Docente Investigador Universidad de San buenaventura Medellín, integrante del grupo autónomo Kavilando. Medelín, Colombia. Contacto: Alfonso.insuasty@usbmed.edu.co
} 


\section{Introducción.}

San Carlos es un municipio del oriente del departamento de Antioquia, quizás uno de los más azotados por el conflicto armado en el país en esta zona del país. Se calcula que cerca del 80\% de su población salió desplazada entre 1996 y 2003 (Centro de Memoria Histórica $\mathrm{CMH}, 2011$ ), quedando su perimetro habitado por entre 4.000 y 5.000 personas de las 25.500 registradas en el censo de 1993 (Olaya, Nunca más contra nadie. Ciclos de violencia en la historia de San Carlos, un pueblo devastado por la guerra. , 2012). Se habla de un desplazamiento forzado de cerca de 18.363 personas entre 1998 y 2006 (Centro de Memoria Histórica $\mathrm{CMH}, 2011$ ) . Ahora bien, según la misma investigación (p. 373) la Acción Social en el año 2011 había registrado en el municipio la salida de 23.015 personas y la declaración como desplazados de 26.169. Si bien el desplazamiento forzado emerge como la problemática y la afectación más visible en el municipio, es importante registrar que estos hechos estuvieron acompañados de cientos de graves violaciones a los derechos humanos e infracciones al derecho internacional humanitario en una guerra cuyo propósito parecía generar un escenario de terror para lograr un control absoluto del territorio.

Por esta razón también es necesario nombrar estos hechos: según el Centro de Memoria Histórica CMH (2011) se han registrado 33 masacres entre 1995 y 2005, cometidas por los diversos actores armados: 22 por los paramilitares, 6 por la guerrilla de las FARC, 1 por otra guerrilla (presumiblemente el ELN) y, finalmente, 4 por grupos armados sin identificar (presumiblemente Fuerza Pública o grupos paramilitares), cuyo saldo fue de 220 víctimas (194 hombres y 26 mujeres). Además de ello, el Centro de Acercamiento, Reconciliación y Reparación de el Municipio de San Carlos "CARE" ha registrado a nivel local un total de 152 desaparecidos (Olaya, 2012), la Asociación de Víctimas de Minas Antipersonales ha registrado 178 víctimas de estos artefactos, y Carlos Olaya registra en su investigación cerca de 634 personas que fueron asesinadas o desaparecidas por los diversos actores del conflicto armado (Olaya, 2012); todo eso unido a la posterior ola de terror y desplazamiento que estas acciones violatorias de los derechos humanos y del derecho internacional humanitario generaron.

Para 2014 la Unidad Nacional de Atención y Reparación Integral a Víctimas del conflicto armado (Unidad de Atención y Reparación Integral a las Víctimas UARIV, 2014) registra que San Carlos tiene una población estimada de 16.036 habitantes y un registro de víctimas de 34.915 , lo que implica un $218 \%$ de hechos registrados sobre la población del municipio. Esto indica que los hechos victimizantes en San Carlos no correspondieron a hechos colaterales, sino que puede inferirse que existió una estrategia dirigida a aterrorizar, golpear y atacar a la población civil, con una intencionalidad clara y explícita de lograr control social, económico, político y territorial por parte de los grupos armados, para lo cual las estrategias de terror y de guerra sucia, aplicadas no sólo en Colombia, sino en toda América Latina (Baró, Sistema, grupo y poder. Psicología social desde Centroamérica II, 1989) han sido instrumento útil en dicho propósito. Es importante mencionar que un número no determinado de personas nunca regresó al territorio y que otra parte de la población actual está habitando el municipio como "reubicados", es decir, personas desplazadas de otras zonas, quienes fueron incluidos por el gobierno en programas de retorno al municipio o quienes viendo una posibilidad de sobrevivencia en estos programas decidieron re-ubicarse en el mismo.

El texto desarrollado en esta misma investigación por el historiador Carlos Olaya (2015) da cuenta de los procesos históricos de represión política, exterminio de movimientos sociales, ejercicio de procesos de control territorial por la vía del terror y la aplicación de diversas formas de victimización, cuyas consecuencias han implicado la destrucción del tejido social, 
el abandono del territorio, la pérdida de escenarios organizativos y de movilización pública, las experiencias de trauma psicosocial y afectación personal y familiar; la pérdida de la confianza, de la cohesión social y de los proyectos de vida de miles de personas y familias.

A pesar de ello, y tal como hemos indagado en la presente investigación, las acciones de resistencia de la población posibilitaron la permanencia de cientos de personas: maestros, campesinos, familias enteras, que resistieron en el municipio y fueron fundamentales para propiciar el retorno de miles a partir del 2007, año en el que la Alcaldía del municipio decretó una emergencia por "retornos" (Centro de Memoria Histórica CMH, 2011) que implicó, a su vez, procesos que desde abajo posibilitaron un regreso masivo de campesinos y pobladores que le han dado nueva vida al municipio. Sobre este proceso presentaremos un artículo que analiza las dinámicas de estas resistencias y acciones desde abajo.

\section{A 4 años de la implementación de la Lay de Victimas 1448.}

Como un abrebocas a la presentación de los resultados de ésta investigación, presentamos un resumen de las dificultades que la Mesa Nacional de Victimas, de las organizaciones sociales, describe a modo de informe, de las dificultades que han encontrado en la implementación de esta ley en materia de reparación.

Dicho informe presenta por una parte, una solicitud directa a la Corte Constitucional de no levantar la figura Jurídica: "Estado de Cosas Inconstitucionales" por el incumplimiento a los derechos de la población víctima del conflicto armado interno, esta figura procede cuando un derecho se ha vulnerado aún y a pesar de activar los mecanismos constitucionales para su protección; es así que por la magnitud, cantidad y nivel de vulneración (en este caso estructural) de derechos, la Corte crea esta figura para hacerle un llamado urgente, alertar y exigir al Estado, tome medidas suficientes y necesarias así como prontas, para superar ese Estado de Cosas que violenta la constitución, en tanto el mismo Estado por omisión o acción, no asume de manera adecuada, la obligación de protección de los derechos de sus ciudadanos, alerta así mismo, el informe, sobre la improcedencia de crear normas en cantidad, creyendo que así se supera dicha situación (ver: Tabla 1).

\begin{tabular}{|c|l|}
\hline \multicolumn{2}{|c|}{ Tabla 1: razones para solicitar se sostenga la figura de Estado de Cosas } \\
Inconstitucional.
\end{tabular}




\begin{tabular}{|c|c|}
\hline 5 & $\begin{array}{l}\text { El aumento de requisitos para la entrega de la indemnización administrativa con } \\
\text { el Plan de Atención, Asistencia y Reparación Integral (PAARI-Decreto 1377/14), } \\
\text { antes no se exigía (ley 1448/11) }\end{array}$ \\
\hline 6 & Se siguen acumulando procesos judiciales como sucedió en la sentencia SU 254/13 \\
\hline 7 & la gravedad de la vulneración masiva continua \\
\hline 8 & $\begin{array}{l}\text { La responsabilidad no es competencia exclusiva de una sola entidad sino de todo } \\
\text { el SNARIV }\end{array}$ \\
\hline 9 & No hay correspondencia entre lo que dicen las normas y los medios para cumplirlas \\
\hline 10 & $\begin{array}{l}\text { Producir excesivamente normas jurídicas, es una estrategia para confundir a las } \\
\text { víctimas y ampliar la burocracia en el Sistema Nacional de Atención y Reparación } \\
\text { Integral a Victimas (SNARIV). }\end{array}$ \\
\hline
\end{tabular}

Fuente: elaboración propia, datos tomados del informe: Avances Y Retrocesos: Ley De Víctimas Y Restitución De Tierras, de la Mesa Nacional de Victimas, de organizaciones sociales (Mesa Nacional de Victimas conformada por organizaciones sociales, 2015).

Dicho informe, además, relaciona algunos elementos que responde a la pregunta ¿qué tanto se ha cumplido de la ley 1448 ley de víctimas y restitución de Tierras?, (ver: tabla 2):

TABLA 2: Dificultades en la implementación de la ley de víctimas

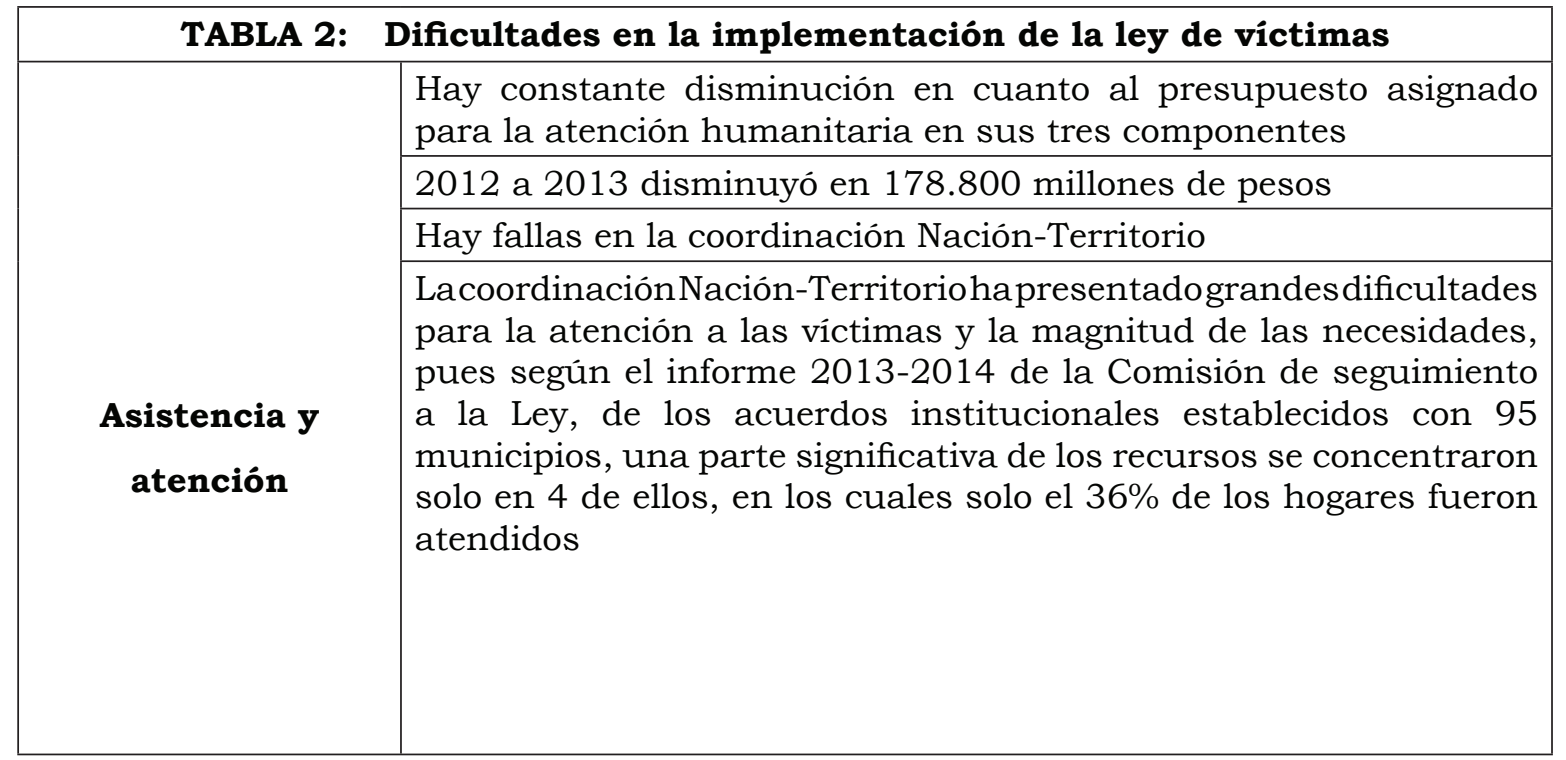




\begin{tabular}{|c|c|}
\hline \multirow{5}{*}{$\begin{array}{l}\text { Reparación } \\
\text { Integral }\end{array}$} & $\begin{array}{l}\text { Para hablar de reparación Integral se requiere que sea: } \\
\text { trasformadora y efectiva (Art. } 25 \text { de la Ley } 1448 \text { ) }\end{array}$ \\
\hline & $\begin{array}{l}\text { La institucionalidad no tiene capacidad para tanto, más bien son } \\
\text { parciales e inexistentes o son más frustraciones que beneficios }\end{array}$ \\
\hline & $\begin{array}{l}\text { La indemnización administrativa, aún no se ha hecho realidad } \\
\text { para casi la mitad de las víctimas incluidas en el Registro Único de } \\
\text { Víctimas }\end{array}$ \\
\hline & $\begin{array}{l}\text { Programa de Atención Psicosocial y Salud Integral a Víctimas - } \\
\text { PAPSIVI- : Tan solo se han beneficiado } 42.696 \text { personas en la } \\
\text { estrategia de recuperación emocional y solo un poco más de } 43 \text { mil } \\
\text { víctimas han sido remitidas al PAPSIVI al finalizar el } 2014 \text {. }\end{array}$ \\
\hline & $\begin{array}{l}\text { Comités Territoriales de Justicia Transicional (CTJT): No cuentan } \\
\text { con el presupuesto necesario en sus Planes Territoriales de } \\
\text { Desarrollo. }\end{array}$ \\
\hline \multirow{3}{*}{$\begin{array}{l}\text { Prevención y } \\
\text { protección }\end{array}$} & $\begin{array}{l}\text { No existe un protocolo o ruta de protección clara; a la fecha van } \\
\text { asesinados } 87 \text { reclamantes de tierras varios de ellos solicitaron } \\
\text { medidas de protección y les fueron negadas }\end{array}$ \\
\hline & $\begin{array}{l}\text { No se tiene en cuenta el principio de buena fe en los procesos de } \\
\text { valoración }\end{array}$ \\
\hline & $\begin{array}{l}\text { Al interior de la Unidad Nacional de Protección no se cuenta con el } \\
\text { presupuesto suficiente para garantizar las medidas de protección }\end{array}$ \\
\hline \multirow{3}{*}{ Verdad } & $\begin{array}{l}\text { La Ley } 1448 \text { no se enfoca exclusivamente en procesos de verdad } \\
\text { judicial (Ley } 975 \text { de2005) }\end{array}$ \\
\hline & $\begin{array}{l}\text { si se han llevado a cabo procesos de reconstrucción de memoria } \\
\text { histórica por parte del Centro Nacional de Memoria, que } \\
\text { documentan el conflicto armado de manera general, con lo que se } \\
\text { intenta dignificar la memoria de las víctimas }\end{array}$ \\
\hline & $\begin{array}{l}\text { Se han establecido los acuerdos para la verdad, con la intención de } \\
\text { que los miembros de las organizaciones y grupos armados relaten } \\
\text { lo sucedido en el marco del conflicto armado como contribución } \\
\text { simbólica a la verdad. }\end{array}$ \\
\hline
\end{tabular}

Fuente: elaboración propia, datos tomados del informe: Avances Y Retrocesos: Ley De Víctimas Y Restitución De Tierras, de la Mesa Nacional de Victimas, de organizaciones sociales (Mesa Nacional de Victimas conformada por organizaciones sociales, 2015).

Ahora bien, en la investigación cuyos resultados presentamos, se desarrolló un seguimiento significativo, desde la perspectiva de la población, sobre las acciones que el Estado en los diversos momentos ha realizado en pro de la reparación de las víctimas en el Municipio de San Carlos, Antioquia, alli se hizo uso de la siguiente metodologia: 


\section{Metodologia.}

Desde nuestro punto de vista pensamos que la valoración de este proceso tendría que hacerse desde la voz de las mismas víctimas, no desde la respuesta estructurada y delineada previamente por encuestas de satisfacción o instrumentos de medición que no logran recoger los significados y experiencias de la gente y que se plantean desde un marco institucional delimitando un marco de respuestas posibles, que generalmente dan poca cabida a la expresión de los sentidos, significados y experiencias vividas por la gente como destinataria de programas y acciones estatales con fines de reparación. Por eso, hemos optado por un método cualitativo, apelando a diversas estrategias metodológicas para triangular información: 12 grupos focales (GF), con la participación de 150 personas, 7 entrevistas individuales (EI) y 5 entrevistas grupales (EG) para completar un número de 170 personas participantes.

Los relatos resultantes, fueron transcritos configurando textos que fueron analizados por el método del análisis categorial por matrices; el cual, es un método que procede de manera analítica: se va avanzando en la interpretación de forma interactiva entre procesos inductivos y deductivos hasta llegar a la construcción de interpretaciones que posibilitan los resultados de la investigación. Una de las características principales del método es la utilización de matrices de análisis, que son un instrumento metodológico para dar orden y claridad, lo que permite visibilizar de modo general las narraciones recogidas, favoreciendo el hallazgo de relaciones entre las categorías de análisis y los discursos.

Los pasos que se van dando en el proceso de análisis es el siguiente: en primer lugar un análisis de coherencia (intratextual), donde cada transcripción se analizó independientemente de las otras, con base en las categorias previamente construidas: se realizó un primer nivel de selección, oración por oración o párrafo por párrafo. Cada sección de texto se asignó a cada una de las categorías. Con lo cual, cada categoría reconfiguró un nuevo texto, aún no ordenado, ni codificado. Posteriormente un análisis intertextual: donde se tomaron los contenidos que aparecen de manera reiterativa, agrupando los elementos compartidos por los relatos individuales, así como lo particular y variable entre cada uno de estos.

Finalmente la codificación teórica que permitió organizar la información según un procedimiento axial, que implica una "depuración y diferenciación de las categorías (conceptos) derivadas" (Flick, 2004)en una relación que vaya de lo general a lo particular, de los conceptos centrales a los conceptos derivados y marginales; de lo que tiene mayor poder explicativo hacia lo que es ejemplo o desarrollo teórico. Este análisis se hizo al interior de la matriz intertextual. Luego se desarrolló el proceso de teorización, ya con el material codificado y disponible, que permitió la elaboración del texto, en el cual se hace visible la voz del investigador, se proponen interpretaciones, hipótesis, desarrollos conceptuales, que a la vez se ilustran con los relatos de los y las participantes, constituyendo un texto que se teje en una unidad de sentido.

\section{Resultados.}

Significados generales en torno a la reparación: ¿Quién debe reparar?. Este contexto de desplazamiento masivo, de múltiples victimizaciones a la población, y posteriormente, de resistencia y retorno le ha planteado al Estado colombiano un reto sin precedentes, puesto que en San Carlos se reproduce en "pequeña escala" lo que ha acontecido a nivel nacional. El país cuenta con cerca de 7 millones de víctimas, que representan el 14\% de la población (Sikkink, Marchesi, Dixon, \& D’ Alessandra, 2014), lo que demuestra la magnitud, la duración y la degradación de nuestro conflicto armado. Según estos investigadores 
de Harvard, "para proporcionar un número tan amplio y sin precedentes de reparaciones, el pais debe pensar de manera más amplia la forma de integrar la politica de reparación en su economía politica. Para reparar al 14\% de la población colombiana, el Gobierno, en su conjunto, deberá incorporar la politica de reparación en su politica macroeconómica. En los próximos años, las reparaciones deberán estar en el centro de cualquier discusión de economía politica en Colombia" (Sikkink, Marchesi, Dixon, \& D’ Alessandra, 2014, p.2).

Es claro, entonces, que la reparación es un deber del Estado y un derecho de las víctimas en el país y, sobre todo en un municipio, donde en su inmensa mayoria, los habitantes fueron víctimas y el Estado también tuvo responsabilidades, tal como lo refieren los y las participantes, ante la pregunta por la responsabilidad de la reparación:

El estado, porque el estado es culpable, es que el estado nos dejó a nosotros solos acá, o sea no tuvimos protección de nadie, al estado no le importó si nosotros comíamos, dormíamos, cuando pasábamos hambre, porque no dejaban pasar los camiones, aquí se pasó hambre pero a nadie le importó eso, cuando se llevaron a la policía y al ejército, ¿quién nos estaba cuidando? nadie, estábamos al margen de quien quisiera entrar o quisiera salir... Yo digo que el estado, para mi es el estado el que debe reparar, porque los grupos armados como tal son ilegales. (GF9).

Para los y las participantes en esta investigación el Estado debe responder por la violencia vivida. En primer lugar porque no garantizó la protección, porque no defendió la vida, honra y bienes de estos ciudadanos, tal como está consignado en la constitución del 91, por qué como es ya demostrado en varios procesos de recuperación de memoria y judiciales, actúo en articulación con grupos paramilitares y mafias en contra de la población civil y en tercer lugar, porque de acuerdo con el marco jurídico internacional y la misma ley 1448, en un Estado de derecho, éste es el que debe garantizar los derechos de las víctimas, dentro de los cuales, el derecho a la reparación es fundamental para la reconstrucción de sus proyectos de vida:

El estado colombiano es quien debe reparar ya que es el que debe proteger honra y bienes de las personas, y no lo hicieron, cuando se presentaron los primeros brotes de violencia, descuidaron la seguridad fisica (GF2)

Ambos relatos, y otros más que obtuvimos en la investigación, nos permiten afirmar que durante los años más crudos de violencia contra la población el Estado Central la abandonó a su suerte (Olaya, La violencia sociopolítica y sus impactos en el municipio de San Carlos, Oriente de Antioquia., 2015). El relato se vuelve reiterativo: de un momento a otro la Fuerza Pública abandonó el territorio, y poco después llegaron los grupos paramilitares con la supuesta misión de derrotar a la guerrilla, pero con la consecuencia real de sembrar el terror en la población, y con ello, aplicar uno de los principios claves de la lógica contrainsurgente: "quitar agua al pez", es decir, golpear a la población civil, "supuesta colaboradora" de la insurgencia para que ésta última no tenga espacio ni territorio de acción (Baró, Sistema, grupo y poder. Psicología social desde Centroamérica II, 1989); (Beristain \& Riera, "Afirmación y Resistencia. La comunidad como apoyo", 1994); (Olaya, Nunca más contra nadie. Ciclos de violencia en la historia de San Carlos, un pueblo devastado por la guerra. , 2012)

...esa reparación la debe hacer el mismo Estado, porque el Estado es el encargado de brindar seguridad y en muchos casos nos dimos cuenta que esa misma violencia fue por parte del mismo Estado... ya cuando ellos se fueron como en tres oportunidades que estuvieron, ya lo mataron y encima le dejaron el panfleto, por colaborador con el ejército, 
entonces creo que ese daño lo debe pagar el Estado (GF10). ...el Estado en sí, está obligado a velar por el bien de la población que esté bien, que tenga vivienda, educación y ¿qué ha hecho el Estado? descuidó salud, educación y todo, la cuidada de los campesinos, porque la cuidada del Estado es para las hidroeléctricas, el Estado no tuvo la capacidad de cuidarnos a nosotros (EI5).

Por esta razón podemos afirmar que el Estado tiene la obligación de reparar, que, incluso con el actual gobierno existe una voluntad política de hacerlo, reconociendo, en primer lugar la existencia del conflicto armado, en segundo lugar, reconociéndose como actor dentro del mismo, y en tercer lugar, sabiendo de sus omisiones y limitaciones para garantizar la vida, honra y bienes de los ciudadanos. La reparación, de acuerdo con la ley 1448 de 2011, con la jurisprudencia desarrollada por la Corte Interamericana de Derechos Humanos y por el mismo derecho internacional, debe desarrollarse en cinco estrategias o procesos: restitución, indemnización, rehabilitación, satisfacción y garantías de no repetición (Sikkink, Marchesi, Dixon, \& D' Alessandra, 2014) (Villa, Londoño, \& Barrera, Reparación a las víctimas de distaduras, conflictos armados y violencia política en sus componentes de compensación, satisfacción, rehabilitación y no repetición, 2015); (Beristain, Manual sobre perspectiva psicosocial en la investigación de derechos humanos, 2010); (Beristain, El derecho a la reparación en los conflictos socioambientales, 2010)

De acuerdo con Sikkink, et al. (2014) y tal como lo ha promocionado la dirección de la Unidad Nacional de Atención y reparación a víctimas del conflicto armado en Colombia (UARIV): "El programa de reparación colombiano es líder mundial en términos del cumplimiento de las normas internacionales de los más altos estándares, y en el abordaje de todos los temas relevantes... (p.1)"

Pero, y aquí está lo que no se publica y lo que es referente para nuestro análisis:

"Con mucha frecuencia, la falta recursos adecuados y de capacidad administrativa Estatal impide el pleno cumplimiento. Algunas veces vemos una mezcla de estos dos problemas. Dada la naturaleza ambiciosa del programa de Colombia y su tamaño masivo y sin precedentes, estos temas de implementación y cumplimiento probablemente se constituirán en un problema, tal como ha ocurrido en los otros casos incluidos en nuestra base de datos. (P. 1)...esto plantea muchos desafios potenciales en el futuro para la Unidad para las Victimas en términos del nivel de expectativas que sin duda genera una politica tan compleja y completa, y las dificultades para cumplirlas" (Sikkink, et. al. P.3).

Es allí donde está uno de los nudos fundamentales de la situación actual de la política de reparación en Colombia, sin que sea claro, todavía, cómo se puede implementar un programa de reparaciones que pueda mitigar realmente el impacto de los daños padecidos por las víctimas del conflicto armado. Nuestra investigación permite acercarse a un territorio que ha sido presentado como prototipo de buenas prácticas estatales en materia de atención, retorno y reparación a víctimas.

Lo primero que constatamos está en la vía de lo planteado en la investigación contratada por la UARIV a la Universidad de Harvard (Sikkink, Marchesi, Dixon, \& D` Alessandra, 2014), en donde se afirma que ante la magnitud de la tragedia en el país, y en particular en San Carlos, la gente no cree en la capacidad del Estado para reparar, puesto que observa que una cosa es el discurso sobre la implementación de las políticas y la concreción de éstas en el papel y en el marco legal. Bien es sabido que Colombia, país "santanderista", suele cumplir con los estándares jurídicos y legales en diversos aspectos de protección de derechos, desde la constitución política, pasando por normas de protección en diversas 
áreas, pero que en la práctica suelen contrastarse con una distancia enorme entre lo escrito y lo vivido por la población. Es claro que a los Estados les interesa aparecer ante la comunidad internacional como cumplidores de los compromisos con las normas internacionales, lo cual expresan por escrito en sus ratificaciones de convenios o en la promulgación de sus propias leyes, y esto, al parecer, les garantiza un cierto respeto en el marco de un mundo globalizado; pero otra cosa es el cumplimiento real de dichas normas; puesto que como ha sucedido en otras latitudes, con frecuencia se tienen problemas para traducir esos compromisos en cumplimiento (Sikkink, Marchesi, Dixon, \& D’ Alessandra, 2014) De allí que la gente del municipio de San Carlos, participante en esta investigación, no vea clara tampoco una plena voluntad de reparación o una concreción de esa política en la vida cotidiana de las comunidades,

...yo digo que en algún momento el gobierno sí apoyó los proyectos, sí nos han dado como algo que hemos perdido, pero el gobierno nunca va a reparar los daños que tuvimos por más que lo intente nunca los reparará... (GF3). ...entonces para mí eso es lo que se dice vulgarmente, eso son pañitos de agua tibia y es que para mí con las harinas que caen de la mesa al suelo, con eso no llena uno... (GF6).

De otro lado, algunos y algunas participantes consideran que además del Estado, deben reparar las empresas que han desarrollado proyectos de "desarrollo" en la región, especialmente, las hidroeléctricas, puesto que asocian su tragedia humanitaria con algunos proyectos de macro desarrollo en la región. Además de esto plantean una pregunta importante: ¿por qué para la infraestructura y las empresas hubo protección y para la población no la hubo? No queda muy claro para la gente este tema, tampoco podemos hacer afirmaciones al respecto, sólo la pregunta que dejan estos testimonios:

...todas esas centrales, bregando a apoderarse de las personas, por eso ahora ya la gente, al menos sabe que le van a quitar; pero también va a estar dando la pelea, usted se va a aprovechar de mi, pero venga pues, tampoco me deje como la vez pasada me dejaron, que me dieron cualquier cosa por mi finca, me dijeron váyase, a los dos o tres meses botaron la platica quedamos tirados en la calle y quién les responde y quién los respeta. Entonces ahora va a ser así, pero la gente al menos ya está peleando, es consciente de que usted me va a quitar esto pero yo también voy a estar peleando para ver qué me van a dejar (EI4).

A partir de estas reflexiones y al analizar la responsabilidad de otros actores sociales y políticos, en relación con las graves violaciones a sus derechos, las comunidades en los grupos de discusión y algunas personas en las entrevistas individuales, manifestaron la importancia de evidenciar la participación de actores económicos que subyacen a la lógica del conflicto armado en la región, la importancia que sean actores responsables en el ejercicio de la reparación. De allí que dentro de los significados construidos en torno a la reparación resalte la importancia de su conexión con la verdad, evidenciando que en el imaginario colectivo construido por las comunidades, el tema de la reparación no pasa solamente por la superación de condiciones de vulnerabilidad, sino que también se hace necesaria la conexión con la verdad y la justicia, tal como lo referencia autores en diversos contextos (Beristain, El derecho a la reparación en los conflictos socioambientales, 2010); (Beristain, Manual sobre perspectiva psicosocial en la investigación de derechos humanos, 2010); (Centro de Memoria Histórica CMH, 2011); (Villa, Londoño, \& Barrera, Reparación a las víctimas de dictaduras, conflictos armados y violencia politica. Parte I, 2014)

...las organizaciones privadas tienen obligación de reparar, las empresas privadas, más en esa zona donde gran cantidad de los recursos se obtienen a partir de los recursos naturales, a uno no le cabe por la cabeza que no hayan tenido complicidad de esta gente. 
Ellos mismos también deberian, hasta qué punto los victimarios deben contar quién estaba detrás de todo eso, una cosa es lo que escuchamos, otra la que hay detrás (GF3).

Y además de estos actores, los mismos victimarios de los diferentes grupos, frentes y actores que, no solamente hicieron la guerra entre ellos, sino que la hicieron fundamentalmente contra la misma población (Pécaut, Guerra contra la sociedad, 2001); (Pécaut, Violencia y política en Colombia. Elementos de reflexión, 2003)

En cierto sentido los victimarios también deben entrar a hacer parte del proceso de reparación, no digamos que directamente, pero sí dando cuenta también de los hechos que todavia hay por aclarar, hay muchas cosas que solamente los victimarios saben y que las victimas no conocen, no conocemos (GF3).

Por esta razón, pensamos y acompañamos una afirmación tajante de la investigación "San Carlos: Memorias del éxodo de la guerra" del Centro de Memoria Histórica (2011): "El Estado tiene que recuperar su legitimidad frente a las victimas y frente a las comunidades, asumiendo compromisos eficaces de no repetición y particularmente, brindando garantias necesarias para que aquellos a quienes la guerra volvió forasteros de su propia tierra puedan recuperar su dignidad, sus haberes y sus plenos derechos de ciudadanos..." (p. 24). Además de ello agrega que se debe avanzar más allá del discurso, los planes y las promesas, para llegar a un goce efectivo real de derechos, algo que aún a 2014/2015 sigue estando en déficit; "esta situación se hace evidente... a pesar de la preponderancia del tema, de la cantidad de instituciones presentes, de los recursos invertidos e incluso de la voluntad politica de sus gobernantes...", puesto que la población "sigue estando en un alto grado de vulnerabilidad... marcada... por la desesperanza que produce una promesa de restablecimiento y reparación constantemente incumplida..." (pp. 410-411), recomendación que también realiza la consultoría de Harvard (Sikkink, Marchesi, Dixon, \& D’ Alessandra, 2014), cuando plantea que uno de los principales problemas en el mundo frente a las reparaciones es el incumplimiento sistemático, en la realidad de la aplicación de las medidas de reparación por parte de los Estados: "en muchos de los programas de reparación de nuestra base de datos, sigue habiendo brechas entre el compromiso y el cumplimiento"( $p$. 5), lo que aumenta claramente las posibilidades de revictimización y dificulta ostensiblemente los procesos de reconstrucción del tejido social (Beristain, "Memoria colectiva y reconstrucción de sociedades fracturadas por la violencia", 2008); (Villa, Consecuencias Psicosociales de la participación en escenarios de justicia transicional en un contexto de conflicto, impunidad y no-transición., 2013)

...reparación para mí, yo digo que de todas maneras muchos proyectos y muchas cosas pero a uno no lo alcanzan a reparar moralmente, eso no se llega a dar, pero de reparación, yo entiendo que reparación sería, para mí sería que el gobierno a uno le diera la forma de uno volver a tener lo que perdió, eso hasta ahora no se ha visto (GF11).

Se evidencia entonces que el proceso de reparación es complejo en la medida en que no puede aparecer como una fórmula copiada y aplicada al pie de la letra, es necesario, además, que este se haga dentro de una lectura del contexto, responsable, profunda y compleja, que considere a los actores protagonistas (las víctimas y las comunidades azotadas por el conflicto), las temporalidades y las necesidades propias de la gente, apuntando realmente a la satisfacción de las mismas; y finalmente, integrando las diferentes medidas: compensación, restitución, satisfacción, rehabilitación y garantias de no repetición (Villa, Londoño, \& Barrera, Reparación a las víctimas de dictaduras, conflictos armados y violencia política. Parte I, 2014). Para que una acción institucional sea o no reparadora es fundamental analizar la significación que las personas víctimas le adjudican al mismo, especialmente 
en términos de su integración en sus proyectos de vida y a la relación que cada sujeto y comunidad establecen entre lo que se les ofrece y lo que han perdido, lo que hace de la reparación una medida que además es íntima, singular y simbólica (Rebolledo \& Rondón , 2010); (Bello, Martín, Millán, Pulido, \& Rojas, 2005); (Beristain, Diálogos sobre la reparación: que reparar en los casos de violaciones de derechos humanos, 2009). Precisamente esta mirada es la que se recoge en esta investigación.

Así pues, queda la sensación que, por el tamaño del daño y la cantidad de pérdidas, la reparación será una tarea casi titánica, casi imposible. No hay confianza en que el Estado pueda hacerlo de una manera efectiva (Centro de Memoria Histórica CMH, 2011), a pesar de los múltiples esfuerzos de la UARIV dentro de sus planes y proyectos para la reparación, que en el caso del municipio de San Carlos, abarca casi la totalidad de la población. Por ahora, puede plantearse esta afirmación del informe del Centro Memoria Histórica CMH (2011): "Lo que predomina es la aplicación de directrices nacionales que, en la mayoría de los casos, no hacen una lectura territorial que reconozca caracteristicas y especificidades de las localidades, las capacidades y limitaciones de los entes locales y sus demandas específicas...” (p. 359). De acuerdo con los y las participantes, se trata de un proceso donde prima la cifra, la cantidad invertida, el número de proyectos realizados, las indemnizaciones entregadas y las acciones institucionales realizadas, pero sin una pregunta directa a los y las destinatarios/as de estas acciones, sin contar con su participación, su proceso mismo de reconstrucción, lo cual es un caldo de cultivo para acciones con daño o procesos de revictimización (Villa, Recordar para reconstruir: El papel de la memoria colectiva en la reconstrucción del tejido social, el empoderamiento colectivo, la recuperación de la dignidad y la transformación subjetiva de las víctimas del conflicto armado en tres regiones de Colombia, 2014); (Villa, Un análisis crítico a la intervención psicosocial con víctimas del conflicto armado en Colombia., Octubre del 2014); (Villa, Londoño, \& Barrera, Reparación a las víctimas de dictaduras, conflictos armados y violencia política. Parte I, 2014); (Villa, Londoño, \& Barrera, Reparación a las víctimas de distaduras, conflictos armados y violencia politica en sus componentes de compensación, satisfacción, rehabilitación y no repetición, 2015).

...hace poco escuchaba la intervención de Paula Gaviria en el Congreso, en una de las Comisiones y hacia una presentación de unas cifras sorprendentes frente a los procesos de reparación, comparándolos con proceso por ejemplo en Guatemala, en Perú, en las Repúblicas Africanas, el nivel de atención en cifras de colombianos es altísima, y decía "bueno, hemos hecho reparaciones individuales y estamos en procesos de reparaciones colectivas y hemos hecho estas indemnizaciones" y en algún momento alguien decía "sorprendente todas esas cifras doctora y cuéntenos ¿cómo han recibido esas comunidades esos procesos?", diciéndole como que la cifra no explica solamente lo que ha pasado y entonces pues claro, es como bajar más al detalle diciendo y de esas cifras qué pasa. Y San Carlos es un municipio que... Alimenta esas cifras muy grandemente (EI3)

En efecto, las cifras que presenta la UARIV dentro del informe de sus acciones al final del primer gobierno de Juan Manuel Santos en el municipio de San Carlos son significativas. De acuerdo con la UARIV (2014) las victimas que han sido indemnizadas en el municipio de San Carlos son 3.574, para una inversión aproximada de 15.506 millones de pesos. Ahora bien, si se dividieran esos 15.506 millones de pesos en las 3.574 personas que se registran como indemnizadas, el monto promedio para cada una sería de aproximadamente 4.4 millones por persona, lo que a todas luces parece una cifra insuficiente como medida de compensación a los daños y pérdidas que se padecieron.

Los y las participantes en esta investigación tienen una conciencia relativamente clara de las implicaciones de lo que se ha hecho en términos de reparación, están informados 
y tienen algunos datos al respecto; por esta razón, pueden deducir que los procesos de reparación individual e indemnización tienen límites, carencias y vacíos en términos de cobertura y en relación con el daño padecido:

Se ha dicho que han indemnizado unas cuatro mil personas pero somos muchas más víctimas que eso, es un proceso que nadie sabe cómo va... (GF2). La indemnización, en la base de datos hay más de 19 mil desplazados y en la indemnización van solo 1500 personas, porque hacen experimentos con la gente y se demoran un rato (GF3)

De acuerdo con la consultoría de Harvard (Sikkink, Marchesi, Dixon, \& D` Alessandra, 2014):

...el tamaño del programa colombiano es, en parte, resultado de la gran escala del conflicto y del número de víctimas, especialmente el número de personas desplazadas, y de la definición tan amplia de los actos de victimización. De hecho, ningún otro caso en nuestra base de datos se aproxima al número de víctimas ya incluido en el Registro Único de Víctimas. Este Registro incluye, actualmente, más del 14\% de la población del país. - incluso- Ninguno de los otros programas ha registrado o reparado a más del 1\% de su población, aunque Perú y Marruecos podrían llegar a beneficiar a un poco más del $1 \%$ de su población a través de reparaciones colectivas. La Unidad para las Víctimas ha compensado ya a un gran número de individuos en un periodo de tiempo relativamente corto: 426.000 víctimas han sido compensadas en menos de cuatro años. En este sentido, la Unidad para las Victimas ha sido muy eficiente en la entrega de compensaciones a las victimas en comparación con otros casos de nuestra base de datos (p.6).

Desde ese punto de vista, se podría afirmar que se han hecho los mejores esfuerzos y se ha puesto la mejor voluntad y se han desarrollado las mejores acciones posibles para cumplir con el propósito de reparación en un país, en un territorio y en un municipio que se ha convertido en emblemático para el país. Aun así, para Sikkink, et. al. (2014) debido a que el programa de Colombia es relativamente nuevo, "es en muchos sentidos aún demasiado pronto para evaluar el grado en el cual queda plenamente implementado y si cumple con las nuevas leyes" (Sikkink, Marchesi, Dixon, \& D` Alessandra, 2014). Sin embargo, para el caso del municipio en cuestión, donde se han desarrollado múltiples acciones, siguiendo diversos marcos normativos, desde el año 2007/2008 (vale recordar que en el año 2008 se empezó a implementar el decreto 1290 de reparación administrativa que comenzó ofreciendo "indemnizaciones Solidarias" de parte del Estado para las víctimas, pero que desconocía la responsabilidad del Estado en el conflicto armado), sí se puede realizar esta mirada, puesto que como municipio que ha sido considerado "piloto", "bandera" y ha recibido otros calificativos, y donde se han invertido ingentes cantidades de recursos, vale la pena realizar esta indagación que pueda dar pistas para una mejor actuación en el resto del país, ya que los relatos construidos por la gente que ha participado en esta investigación, difieren en varios aspectos importantes de los enunciados por la oficialidad:

...que el municipio plan piloto, a nivel nacional, en reparación y en todos los temas de las victimas es San Carlos y eso es una plena mentira. Me ha dolido mucho porque a San Carlos que es el municipio que muestran como ejemplo de retorno en Colombia y en el mundo, al cual le han hecho mucha publicidad, demasiada publicidad, que todavia estamos alrededor del 50\% sin resolver... (EG1). Le puedo decir a usted que en el municipio piloto del pais hay hambre. Sí. Por eso le digo, porque a mi me ha tocado ver tanta gente, cómo se han reparado una cuantas, yo diría sinceramente que acá en San Carlos reparadas o medio reparadas un 10\%, mejor dicho, asistidas (EG2). 
Podría decirse que lo que pase en San Carlos puede ofrecer un punto de contrastación más que significativo de lo que puede estar pasando o puede pasar en el resto de los otros municipios del país. Puesto que es quizás el municipio de Colombia, fuera de las grandes ciudades, que ha recibido mayor atención, oferta institucional y acciones reparadoras de todo el territorio nacional.

Ahora bien, uno de las primeros detalles que pueden señalarse en las cifras tiene que ver con el hecho que de la cantidad de víctimas indemnizadas (3574), sólo cuentan con plan de atención, asistencia y reparación integral (PAARI) 1.761. Es decir, más de la mitad de las indemnizaciones se ha hecho sin tener un marco amplio de acompañamiento para la reparación integral, por lo menos en los términos planteados por el plan de reparación integral propuesto por la Unidad nacional de atención y reparación a víctimas; lo cual será evidenciado más adelante en los testimonios y relatos de la gente, en la medida en que hay manifestaciones de malestar colectivo en relación con las indemnizaciones. Para responder a esta situación la UARIV presenta en su informe, la realización de 58 ferias (A nivel nacional) para un proceso integral de reparación: "Las ferias integrales de servicio "Indemnizaciones Transformadoras" son una estrategia para presentar la oferta institucional a las victimas del conflicto armado en el marco de un proceso de reparación integral. Adicionalmente, se pretenden consolidar como un espacio a través del cual se realice la complementariedad de las otras medidas de reparación, tales como: rehabilitación, satisfacción, restitución y garantias de no repetición. Lo anterior, se materializará a través de la participación de entidades del orden nacional, departamental, municipal, privado y de cooperación internacional, dado que las victimas podrán acceder a una oferta de programas, proyectos y servicios que cumplan con las necesidades identificadas en el PAARI" (Unidad de Atención y Reparación Integral a las Víctimas UARIV, 2014)

La idea es poder generar escenarios para una mejor inversión de los recursos para la superación de condiciones de vulnerabilidad generada por la victimización en el conflicto armado, además prevenir el mal gasto de estos recursos: "para ello durante el año 2013 se llevaron a cabo en el municipio de San Carlos 18 Talleres de Educación Financiera al que asistieron 1.154 victimas del conflicto armado". (Unidad de Atención y Reparación Integral a las Victimas UARIV, 2014). Sin embargo, algunos y algunas de los y las participantes manifiestan que este proceso tiene limitaciones serias, en cuanto a sus alcances y posibilidades, de generar una acción de reparación transformadora; y que por el contrario, es posible que puedan ser potenciales generadoras de daño:

Cuando hablaba ahora de reparación, yo la escuchaba a ella, ella de pronto se mide mucho porque trabaja con una institución, yo también trabajo con una institución, pero es defendiendo los derechos... entonces uno dice y se lo digo a ustedes, ¿ustedes si creen que una víctima de la violencia es reparada con un incentivo que el Estado en este momento le está dando a cada uno individualmente? Eso no es una reparación, eso no es una reparación, yo incluso estoy esperando la reparación mía... (EG2)

Por lo tanto, para analizar toda la información académica y mediática que se viene impartiendo desde el gobierno central, para pasar por el tamiz de la experiencia de la gente estas afirmaciones y acciones que se están ejecutando a nivel central, se hace urgente recoger los significados que la gente le ha venido dando a este proceso de reparación, entendiendo que el principal responsable de la misma es el Estado, y que el actual gobierno ha pretendido mostrar que en efecto es así y se está haciendo cargo.

$¿$ ¿De la reparación individual a la reparación colectiva?. De otro lado, y ante la evidencia que implica una reparación centrada en la indemnización, la Unidad de Atención y Reparación 
Integral a las Víctimas UARIV (2014) presenta en su informe que "la comunidad de San Carlos inició la implementación de la ruta de reparación colectiva en el mes de noviembre del año 2012... teniendo en cuenta las graves violaciones a los derechos humanos que toda la población de este municipio había sufrido". Posteriormente, se realizaron las consultas respectivas y se definió la voluntariedad del municipio para realizar dicho ejercicio. Según el informe referenciado: "durante la fase de alistamiento, se brindó información clara y oportuna con el fin de identificar las necesidades y expectativas de la reparación... Entre los meses de abril y agosto del año 2013 se implementó la fase de alistamiento con la comunidad de San Carlos, con cuatro encuentros, en los que se abordaron los siguientes temas:

- Ruta de reparación colectiva.

- Memoria histórica y derecho a la verdad.

- Derechos Humanos y Derecho Internacional Humanitario.

- Sujetos de reparación colectiva.

- Presentación de la estrategia Entrelazando" (Unidad de Atención y Reparación Integral a las Víctimas UARIV, 2014)

Al finalizar esta fase se concretaron una serie de acuerdos para llevar a cabo en la siguiente fase de la ruta de reparación colectiva: fase de diagnóstico del daño. Para la cual se desarrolló un trabajo que recogiera los materiales desarrollados en anteriores investigaciones, siendo de vital importancia la investigación realizada por el Centro de Memoria Histórica (Centro de Memoria Histórica CMH, 2011), cuyo informe y recomendaciones fue clave en el proceso de construcción de la propuesta.

Así pues, se pretendió realizar un ejercicio colectivo que definiera el plan de reparación colectiva. Sin embargo, la mayoría de los y las participantes se sienten ajenos a este proceso y han construido un imaginario colectivo que se ha desplegado por todo el municipio, donde se reconoce que la reparación colectiva se centra en la pavimentación de la carretera Granada - San Carlos, y otras obras de infraestructura, objetivo fundamental del gobierno municipal:

Se ha trabajado, socializando con veredas, gremios y demás. Muchas iniciativas para la comunidad no se suspendieron, se hicieron periódicamente y después de muchos ejercicios se decidió que esta reparación tenga una obra: la pavimentación de la vía San Carlos - Granada. Ya somos el primer municipio que tenemos demanda registrada, como cuando uno se viene desplazado, nosotros la hicimos de primero y varios municipios están solicitando una reparación, San Carlos esta de primero pero se hizo la declaración mas no la reparación. La nación vino, convocó a la gente y se logró una especie de convenio con la nación para hacer la reparación colectiva hasta nos felicitaron, se convino en reparar colegios, caminos, carreteras pequeñas, la carretera San Carlos-Granada, Puerto Garza-Samaná, San Carlos-Jordán, muchas cosas de esas (GF1). El plan de reparación colectiva a nivel municipal... apenas se socializó y se centralizaron fue en pavimentación San Carlos-Granada y hace más de 10 años se está hablando eso. Ese plan de reparación ya se socializó, es un proyecto que se va a ejecutar, está muy bien, pero es mentira en 3 años solo estructuraron la cofinanciación (GF4).

Los y las participantes en esta investigación no se han sentido partícipes de esta idea, y en algunos casos afirman que a los talleres consultivos, la administración municipal se encargó de, o bien, llevar personas afines a su idea de promover la pavimentación de la carretera, o bien produjo un libreto anterior que hizo centrar la discusión en este tema:

Lo que pasa es que el concepto de reparación colectiva viene es de los funcionarios de la Alcaldía, ellos más que todo viene es de allá porque en el desespero de ver pavimentada 
la vía de acá a Granada y para hacer campaña también, salió ese término, reparación colectiva, es que si no quieren pavimentarla, vamos hacer una propuesta de reparación colectiva que nos pavimenten eso, pero yo creo que a ninguna de la gente del pueblo nos tuvieron en cuenta para eso, no preguntaron ¿Usted quiere reparación colectiva? (GF 10).

De todas formas en el marco de las acciones de reparación colectiva la UARIV reporta la construcción de tres puentes en vías veredales, entregados el 14 de junio de 2014 en el marco de los procesos de retornos y reubicaciones, lo que ha implicado el mejoramiento de infraestructura que, en concepto de la Unidad, contribuyen a mejorar la calidad de vida de los habitantes, con el ánimo de que puedan recomponer el tejido comunitario. "El suministro de materiales para estos puentes, especificamente tuvo lugar en las veredas Las Palmas, La Aguada y La Esperanza. En todos estos casos el aporte de la Unidad fue aproximadamente del 90\%" (Unidad de Atención y Reparación Integral a las Víctimas UARIV, 2014)

Este tipo de acciones genera reflexiones que recogen algunas inconformidades, o incluso expresiones que están cargadas de dolor, otras evidencian que quizás el proceso no se hizo cómo tendría que haberse hecho y evidencian las dificultades para lograr un consenso al respecto.

...la gente se capacita pero debe aclararse mejor, la reparación colectiva todavía no es un hecho... yo creo que eso debería ser de otra manera, es que no lo han sabido hacer $y$ aqui hay intereses de todas partes y de la gente aprovechada (GF2). Para poder que pavimenten una carretera tuvieron que matar un montón de gente, haber violencia. Eso es de años atrás (GF4).

De todas formas en la mayoria de los y las participantes se expresa un malestar por esta situación, y si bien, todos reconocen que es importante la pavimentación, esta no se debería asociar con la reparación como proceso de reconstrucción del tejido social, puesto que puede implicar una "banalización" de la muerte y desaparición de cientos de personas en el municipio, del dolor y el terror sufridos. Se hace claro que es fundamental diferenciar lo que significa una politica social, una política de infraestructura, de una acción reparadora. Y si bien, la pavimentación de la carretera y otras obras de infraestructura pueden ser un ejercicio de la nación para saldar una deuda histórica con un municipio, es claro que como centro de la reparación colectiva, puede terminar siendo una forma de eludir otras dimensiones fundamentales que deben estar implicadas en el ejercicio de reparación:

Alguna vez en una reunión alguien hablaba, que una parte habian dicho que habian hecho una solicitud de lista de peticiones para reparación del municipio y que la prioridad era la reparación de la carretera como muestra de reparación, yo me quede atónita porque eso no es reparación, cómo va a ser pavimentar reparación; le da tristeza a uno porque le sustentaron a uno que en una asamblea el 80\% de la población pidió eso, eso es asistencialismo, eso son obligaciones del gobierno. Todavía la comunidad de San Carlos no ha dimensionado qué es reparación... Atención psicoafectiva no se ha hecho, reparación individual los dos centavos o el millón que le dan a unos y otros, puede llenar el vacio, bien, y la reparación colectiva se considera que con la guerra se rompió una cultura de compartir tantos productos entre los municipios, lo único es buscar la forma de que al menos la pavimentaran (GF4).

Relaciones y confusiones entre ayuda humanitaria y reparación: De acuerdo con lo abordado hasta este punto, también en el plano individual emerge entonces una confusión que se presenta tanto en las instituciones del orden municipal, departamental y nacional, como en los habitantes del municipio de San Carlos, puesto que en gran medida no existe una clara diferenciación entre reparación, planes de retorno, ayuda humanitaria, proyectos 
productivos y otras acciones del Estado. Tampoco se tiene claridad de donde vienen los recursos, si de la nación, del municipio o del municipio de Medellín, de la cooperación internacional o de la empresa privada, todos actores sociales, económicos y políticos en los procesos de retorno y reparación. Por lo tanto, el análisis de los significados sobre la reparación pasa por un primer imaginario que sigue siendo muy fuerte en la población: la gente en muchos casos, habla de ayudas o beneficios, pero no de unos derechos que se están resarciendo,

Personalmente, en mi vereda cuantas personas han adquirido las ayudas ¿qué les han dado? ¿Cuándo han ido psicólogos en reunión colectiva? Les han dado semillas, ayudas para la casa. Todo no es malo del todo, si nos han ayudado, algunas personas no sienten la ayuda que les llegan y no han podido hacer lo que querian pero al menos les llegó la ayuda, entonces ha sido ayuda, poquita, pero se ha visto... Muchas de las ayudas que vienen no son con plata del Estado, sabrá dios de dónde vienen porque a veces hablan como en otro idioma, posiblemente en alemán son capaces de decir que aquí la plata es para otra cosa (GF4).

Las cifras también registran que se han atendido por la vía de la ayuda humanitaria 8.066 entre 2010 y 2014, durante el primer período de gobierno de Juan Manuel Santos, con una inversión aproximada de 5.667 millones de pesos (Unidad de Atención y Reparación Integral a Víctimas UARIV, 2014); si aplicamos el mismo ejercicio que con la indemnización resultaría que lo que se ha entregado, en promedio por persona, serian $\$ 702.257$, en un periodo de 4 años, lo cual resulta irrisorio en relación con las experiencias de vulnerabilidad, exclusión, empobrecimiento, y en muchos casos, sufrimiento extremo que la población ha tenido que vivir. Por esta razón, entre otras, para algunos y algunas participantes es importante reconocer que la recepción de ayuda humanitaria no ha implicado que hayan sido reparados todavía,

No me han reparado de ninguna manera, ni con ayudas ni con nada, ni con platos de arroz, ni nada, solo ayuda humanitaria cuando la he necesitado. La ayuda es una ayuda que le dan inicialmente cuando esta desplazado, con unas tablas que no las cumplen, a medida que uno pide más si demanda, eso no entra en la reparación, solo es una ayuda que inclusive debe ir acompañada de comida, techo, cualquier cosa- no he sido reparada de ninguna manera (GF1).

Si bien las instituciones tienen claro su propósito, su mandato y su acción, no han logrado establecer una relación con las comunidades que permita una comprensión clara del horizonte de las acciones que se están desarrollando. Así pues, una primera falencia tiene que ver con la escasa comprensión de estas mismas instituciones en relación con la ejecución de su acción. De otro lado es importante comprender que el contexto del marco jurídico-político para el trabajo con la población cambió en el año 2012. Antes de esto, buena parte de los procesos que se hacían estaban relacionados con los retornos de población al municipio, en los cuales las acciones del Estado estaban enmarcados en las políticas públicas emanadas a partir de la ley 387 de 1997, llamada ley de desplazamiento forzado. Es decir, buena parte de las acciones se concretaron en procesos de apoyo al retorno y reubicación de población.

Posteriormente, algunas indemnizaciones a víctimas de homicidios, básicamente, se hicieron en el marco del decreto 1290 de 2008, denominado de reparación administrativa; a través del cual el Estado ofrecía una indemnización "solidaria" a las víctimas de este tipo de hechos. Finalmente a partir de enero de 2012 que entró en vigencia la ley 1448 de 2011 y sus decretos reglamentarios, el marco normativo cambió: el desplazamiento forzado 
se tipificó como una forma de victimización, se agregaron otros tipos de victimización y se realizó una tabla de indemnizaciones que buscaba una cierta proporcionalidad con los hechos acaecidos. Se unificó la política de atención a víctimas con la de atención a población en situación de desplazamiento, y a su vez se definió una política pública de reparación para todas las víctimas, incluyendo a los desplazados.

Estos giros normativos, incluyendo los aportes que hace la ley 975 de 2005, y las sentencias de la Corte Constitucional en materia de seguimiento en la atención a la población desplazada, hacen que haya una cierta complejidad en las formas estatales, movimientos institucionales que no han posibilitado en la población una comprensión más nítida de los diversos escenarios que, en primer lugar, permitan distinguir las politicas y las acciones dirigidas a la atención de las víctimas (atención de emergencia, ayuda humanitaria, procesos de retorno y reubicación), de las de reparación, que comprenden las medidas de indemnización, rehabilitación, restitución, satisfacción y garantías de no repetición. Y finalmente, en muchos casos, estos dos tipos de medidas no se diferencian de las políticas sociales de atención que debe implementar el Estado para garantizar derechos económicos, sociales y culturales de la población. Por lo tanto, las confusiones son múltiples y los cruces en el análisis no son fáciles de realizar,

Yo entiendo que ha habido un proceso de reparación supuestamente en San Carlos y que hay muchas personas que aparecen como retornados y es que ha habido cosas muy raras, porque a los que estaban en el 15-10 les han reparado una parte, con mentiras, les han dado unas cartas con auxilios para ayudar a conseguir la casa pero eso está en el aire. Les dieron unas por 16 y 17 millones y ayer confirmaron que no, que eso es aparte, los auxilios son para comprar casa en cualquier parte. Ha habido diferentes casos, la gente que no está dentro de los programas queda siempre por fuera... (GF1). Supuestamente a los que les lleguen la ayuda de la indemnización, les han hecho mejoramiento de vivienda, les han hecho proyectos productivos; o sea que si deben tener viviendas... Pero mucha gente no la tiene o no les ha llegado... (GF6)

Desde este punto de vista los análisis a realizar tocan, por tanto, no solamente las políticas de reparación, sino también, las políticas de retorno de población desplazada, atención a las víctimas, ayudas humanitarias y algunas politicas sociales en materia de salud, educación, infraestructura que corresponderian claramente a obligaciones del Estado sin que mediara ningún conflicto armado. Este tipo de confusiones podría aclararse con el concepto "reparación transformadora" (Sikkink, Marchesi, Dixon, \& D’ Alessandra, 2014); (Uprimny Yepes \& Guzmán Rodríguez, 2010); (Villa, Londoño, \& Barrera, Reparación a las víctimas de distaduras, conflictos armados y violencia política en sus componentes de compensación, satisfacción, rehabilitación y no repetición, 2015) donde se plantea que en un contexto de pobreza y vulnerabilidad estructural de las víctimas, la reparación no solamente debería conducir a esta población al "estado anterior" a la violación de sus derechos, sino que tendria que intentar llevar a estas personas a una situación mejor que le permita superar sus condiciones de vulnerabilidad. Ahora bien, en primer lugar tendríamos que preguntarnos si esto es lo que realmente está ocurriendo, porque en sus relatos la gente da cuenta de una situación de precariedad en relación con el estado anterior a su desplazamiento y/o victimización; pero además, este concepto (reparación transformadora) no puede ser un pretexto para suplantar las políticas sociales del Estado a través de los programas de reparación, puesto que esto produce un efecto adverso y pernicioso: el hecho que muchas personas se quieran hacer pasar por víctimas para poder acceder a los beneficios sociales del Estado. 
Es que ahí es donde está el problema que en Colombia, teniendo en cuenta la gran cantidad de victimas que hay lo programas sociales que tiene el estado la obligación de brindarle a sus ciudadanos por el artículo segundo de la constitución, los fines del estado se han confundido con los programas de reparación y eso si es un cuento muy grande, porque acá por ejemplo en San Carlos uno ve que para acceder a cualquier programa básicamente si usted no tiene su código de desplazado, es como si usted no tuviera derechos, entonces la gente me dice y me pasa mucho, entonces porque yo no me desplacé yo dejo de ser ciudadano, ahí es donde está el asunto, ahi lo que hay es un asunto filosófico y politico que hay que revisar y es eso que como en Colombia no hay un modelo que le permita decir que todos los ciudadanos sean víctimas, pero no victimas tiene derechos a programas sociales esos apuntan en un lado, pero estas victima sea usted de estrato 1, 2, 3, 5 o 6 también tienen derecho, esa es la grave confusión que tenemos ahora... (EI2)

Por esta razón, y en otro contexto, Utas, M. (2005) se pregunta por los marcos, esquemas y formatos que se abren desde las intervenciones humanitarias, las comisiones de la verdad, los procesos de reparación y otros formatos desarrollados por la comunidad de derechos humanos, que pueden generar formas de interacción con las poblaciones, que más que responder a sus necesidades, plantean formas que no logran acertar en lo que la gente necesita, y no logran llegar al meollo de la problemática para realizar la reparación. Con lo cual, el resultado es que se pueden generar relaciones asistencialistas y paternalistas, donde la gente se pone en un lugar de subordinación y sometimiento que no posibilita la reconstrucción de la autonomía y de su posición como sujetos de derechos:

Para mi la ayuda humanitaria es limosna... porque en condiciones normales si no me hacen daño, no tiene por qué darme ayuda humanitaria, si hay un Estado garante de los derechos como están en la constitución, nadie tiene porque darme nada y antes no nos daban nada, el campesino veía al estado representado en los territorios ¿a qué? A pagarle impuestos y a utilizar los funcionarios encargados de resolver esos conflictos que se daban y se han generado y se generaran siempre en nuestras sociedades, pero si esos recursos son destinados para que se cumplan los derechos fundamentales, no tiene por qué darme la ayuda humanitaria, porque ya me dieron la oportunidad de estudio, que es un derecho fundamental; me están garantizando la salud, entonces esos recursos los deben estar es gastando ahi, tengo garantizada la salud, la posibilidad de empleo o generación de ingresos en el campo dónde esté, entonces no tienen que darme allá, los no sé qué, porque considero que eso, para mi es maligno (EI1).

Este tema ha sido mucho más evidente en relación con la vivienda: uno de los puntos centrales de los proyectos de retorno en la Alianza Medellín-San Carlos, familias en su tierra o en el Convenio 15-10, entre otros, ha sido el de vivienda; al parecer orientados a una política de apoyo al restablecimiento de la población desplazada; y esto en algunos casos se confunde con la indemnización o con otras medidas de reparación:

Yo he estado con el banco para sacar una tierra, asi como para vivienda, pero no hay posibilidad porque es a largo plazo y uno con qué da las cuotas (GF12). Se ha hecho mucha reparación en vivienda nueva, en mejoramiento de vivienda y con apoyo de Medellín. En el de vivienda, la mayoría del pueblo ha sido beneficiado por la vivienda, fue algo que se le hizo, no le dieron la plata para que lo hicieran sino que se lo hicieron, me parece que muchas viviendas se mejoraron (GF3)

Aún más, estas confusiones se han dado no sólo en la gente, sino también en el entramado institucional que ha intervenido en el municipio, haciendo que, incluso, las instancias municipales no tengan muy claro qué tipo de acciones y con qué fines se están desarrollando 
en su jurisdicción. Así pues, hay planes de construcción de vivienda, de mejoramiento de vivienda, está la politica nacional de vivienda gratis, acciones de organizaciones internacionales para la vivienda, y una serie de acciones institucionales donde no se logra delimitar el proceso de reparación de la política social implicada. De otro lado, algunos funcionarios y programas plantean que el apoyo para construcción, mejoramiento o compra de vivienda hace parte de los derechos de "compensación" que el Estado les ofrece a las víctimas. De tal manera que, como se viene enunciando no se pueden clarificar los escenarios en los cuales el Estado está asumiendo una "deuda histórica", está en el ejercicio de una política social a la que está obligado constitucionalmente, o realmente está desarrollando acciones de reparación a las víctimas del conflicto armado:

Entonces debido a eso ya dijeron que el primer incentivo que se va a entregar, a los que no se les ha entregado es el de hábitat, que antes era $R C B H$ reducción de carencias básicas habitacionales, entonces ya gracias a que nosotros de tanto intervenir de tercos, entonces ya dijeron tienen toda la razón, la principal necesidad es la de vivienda, aunque se podría llamar mejoramiento de vivienda porque es reducción de carencia, porque el monto que da, porque mejoramiento de vivienda es de cinco millones para arriba, entonces esto los está vetando para acceder por medio de la administración a un proyecto de mejoramiento de vivienda, porque ya van a solicitarlo y le dicen pero usted está en tal programa ya les dieron, que es un millón doscientos veinticuatro mil para hacerle un mejoramiento a una vivienda o para implementar una habitación siquiera (EG2).

A su vez, estas instituciones establecen con la gente y con el mismo municipio relaciones de tipo vertical, no dialógicas, que genera situaciones en las cuales la gente se ubica en el lugar del "ayudado", del "beneficiario" de un proyecto, y no como un sujeto social y político actor de su propia proceso de desarrollo y transformación de su realidad, como sería necesario desde una óptica de reparación que reconoce al sujeto político y de derechos y por lo tanto, actúa para "reparar" las vulneraciones padecidas. Por esta razón algunos participantes se preguntaban por los hilos que se tejen en estos escenarios: ¿quiénes ganan con estas confusiones? ¿Qué esperan las instituciones cuando la reparación se plantea en términos de ayuda? ¿Qué fines puede haber alrededor de unos programas que asumen el orden de lo asistencial y no logran un ejercicio de reconstrucción de la subjetividad ni de la ciudadanía?

E: ...cuando dices maquiavélica es como que el estado tuviera una intencionalidad al dar la ayuda, o sea, que pretende con dar la ayuda, además de paliar el daño.

$P$ : paliar el daño, para mantenerte simplemente dormido, para que tu no pienses como vas a solucionar tus problemas, la gente bendice al gobernante que está patrocinando, que pasó acá, todo tipo de atrocidades, porque simplemente va y le estira la mano y le da, la libra de arroz y él se queda con las 23 libras restantes, por ejemplo. Yo soy de las que considero, que necesitamos un Estado garante de derechos, pero no que patrocine mendicidad (EI1)

A pesar de lo anterior, en algunos de los grupos focales y en las entrevistas encontramos relatos que permitieron identificar en la gente una reflexión sobre esta realidad, lo que evidencia una diferenciación entre reparación y asistencialismo, lo que permite nombrar que aún, y a pesar de las cifras del Estado, la "ayuda" viene desde arriba, se da desde arriba y se acerca más a paños de agua tibia, que a un proceso de reparación integral y transformadora, por lo menos en los términos planteados por la misma política pública, en el papel.: "Para uno decir que se siente reparado yo creo que falta mucho, porque no nos han dado sino pañitos de agua tibia, ayudas si, pero ninguna, todo es de a poquitos" (GF1). 
Así la reparación integral, al final, es una promesa que no se cumple. Por lo tanto, aunque se observa una lógica de sobre-intervención en el municipio, no se logra el propósito; puesto que las metodologías asistenciales centradas en la entrega de "beneficios" económicos, va dejando la sensación en una parte de la población de impotencia, de ocupar un lugar de segunda categoría, no experimentar la satisfacción que implica una reparación, como se afirmó en varios grupos y entrevistas: "nos están volviendo limosneros",

El gobierno no sabe cómo organizar el problema, esperando, haciendo filas inmensas, que nos van a regalar y a nosotros nadie nos regala nada. Porque para qué sacaron esas leyes, que reparen, pero que no digan que van a regalar. Todo es un enredo, empiezan a hablar el concejal, el gobernador, el otro (GF1). El Estado fue muy hábil en hacer ver el conflicto de una manera asistencial, todo el mundo habló del asistencialismo y al Estado le encanta eso, que la vaca, la plata, la casa. No podemos pensar así (GF4).

De allí que una participante exprese de manera clara:

No me hagan daño para que no me tengan que dar limosna, pero el Estado te da limosna para disimularte el daño... entonces vuelve la burra al trigo, nos volvieron limosneros, para que los gobernantes pudieran hacer lo que quisieran y enseguida para que otros organicen su vida y tengan empleo, vienen y me dan la limosna y enseguida me dicen que venga y abra el ojo, no... (EI1).

Por tanto, se termina percibiendo la "ayuda" como un paño de agua tibia que no es suficiente para reparar el daño, se genera una profunda insatisfacción, que al mismo tiempo promueve actitudes en la población de buscar siempre la "asistencia" y no una acción transformadora. Así pues, si se analiza en perspectiva relacional, esta lógica de intervención asistencial va generando en la misma población, desaliento y desesperanza, porque siempre queda la sensación que la "reparación" viene en migajas y que no se puede experimentar realmente el resarcimiento de un derecho: "Porque la perdi, pero a mi me hicieron fue un mejoramiento, entonces para mí eso es lo que se dice vulgarmente, eso son pañitos de agua tibia y es que para mí con las harinas que caen de la mesa al suelo, con eso no llena uno..." (GF6).

Así pues, es importante afirmar que la reparación no es un regalo ni una ayuda, es un derecho que tiene la población, que tienen las víctimas. De allí que las acciones del Estado y las instituciones que contrata para su ejecución deben estar orientadas en esa perspectiva, lo cual parte de la misma construcción de la relación con la gente, tal como se profundizará en el tema de la acción con daño y la revictimización (Tema que será abordado y profundizado en otro capítulo / artículo de esta investigación). Una acción desde la verticalización y un lugar de poder, que ubica la relación no como la reivindicación de un derecho, sino como una obra de caridad, termina por generar en quien la recibe un sentido de agradecimiento, pero al mismo tiempo dependencia y pérdida de autonomía, con lo cual pasa a ocupar el lugar de "mendigo" o dependiente de la ayuda "paternal" que recibe.

...porque ¿qué ha pasado? el mismo modelo de intervención ha generados eso en el pueblo, en la gente, deme, deme, deme, entonces es un asunto que también tiene parte y parte, parte del estado por el modelo de intervención que generó, pero parte de responsabilidad también de los ciudadanos... (EI2)

Ya el informe del centro de Memoria Histórica afirma que las "ayuditas" terminaban siendo un proceso de invisibilización de los derechos, además de tener el riesgo de convertirse en un medio para el ejercicio del poder, la entrega de dividendos políticos, el pago de favores y otras argucias del ejercicio político en nuestro país (Centro de Memoria Histórica 
$\mathrm{CMH}, 2011)$. Se tiene entonces que las actitudes, percepciones, expectativas y demandas de reparación son diferenciales para las personas víctimas de un territorio, siendo estas especialmente importantes para aquellas que se encuentran bajo condiciones de pobreza y exclusión. Este panorama puede dar lugar a la manipulación, competencia y utilización política de estas personas, que se debaten entre las demandas de dignificación y justicia y las de satisfacción de sus necesidades básicas y que tienen un profundo desconocimiento de sus derechos y de los mecanismos para hacerlos valer (Gómez Isa, 2006); (Jaramillo Marin, Reflexiones sobre los usos y abuso de la verdad, la justicia y la reparación, en el proceso de justicia y paz colombiano (2005-2010), 2010); (Jaramillo Marín, Narrando el dolor y luchando contra el olvido en Colombia. Recuperación y trámite institucional de las heridas de la guerra, 2010)

A todas las cosas de victimas la gente lleva un costal. Hasta yo. Hacia allá es donde apunta la reparación, la gente ya cuando le hablan de reparación de victimas llevan un costal, llevan de todo para ver que les van a dar. A la gente la acostumbraron a esa parte... El mismo Estado (GF10).

\section{Conclusiones:}

Esta revisión a la política de reparación del Estado Colombiano en el municipio de San Carlos, es un aporte más, dentro de las contribuciones que reflexionan e intentan repensar las formas en que actualmente se están desarrollando los procesos de reparación en Colombia. Una cosa es que Harvard diga que tenemos las mejores políticas públicas de reparación en el mundo, pero en el papel. Y otra los significados y construcciones sociales que se están desarrollando en los escenario cotidianos de las víctimas. En este sentido, también para nosotros San Carlos es prototípico. Si este es el municipio que se presenta y se exhibe en espacios nacionales e internacionales, al escuchar y recoger las experiencias y significaciones de la gente en sus voces y relatos, nos lleva a afirmar que estos mecanismos y procesos de reparación en Colombia, están evidenciando algunas fallas graves y algunos aciertos mínimos desde la perspectiva y el interés de las personas víctimas. No se está desarrollando un proceso efectivo, sino, en algunos casos, revictimizantes, y esto puede implicar problemas para lograr el objetivo de promover la transición de la guerra a la paz, la reconciliación nacional y la recuperación de las víctimas.

Por esta razón puede afirmarse que los temores de la investigación de Harvard (Sikkink, Marchesi, Dixon, \& D' Alessandra, 2014), pero también lo planteado en los artículos publicados por esta misma investigación (Villa, Londoño, \& Barrera, Reparación a las víctimas de dictaduras, conflictos armados y violencia política. Parte I, 2014); (Villa, Londoño, \& Barrera, Reparación a las víctimas de distaduras, conflictos armados y violencia política en sus componentes de compensación, satisfacción, rehabilitación y no repetición, 2015) sobre el estado de la cuestión en estos temas, en Colombia, debido a sus condiciones contextuales, a las restricciones institucionales de la forma como se realizan los procedimientos en el Estado Colombiano, y a los intereses que hay en juego, que no favorecen el empoderamiento de las víctimas, existen importantes dificultades para hacer realidad la reparación integral y transformadora a las personas víctimas, desde los propios marcos de significación de estas últimas. Por esto se pueden evidenciar en sus relatos que estas acciones han generado en éstas efectos contrarios a los esperados, revictimizándolas, impactando en su identidad y en el tejido social, con lo que se exacerba el daño e impacto producido por el conflicto armado. Este tema lo abordaremos con mayor profundidad en un próximo texto. 
De acuerdo con lo anterior se hace necesario idear y ejecutar acciones adecuadas y no victimizantes para aproximarse a las significaciones de las víctimas, en su contexto, con sus marcos culturales y sociales, en aras de lograr procesos de reparación realmente eficaces y, sobretodo, dignificantes. Es imperativo que dichas acciones obedezcan a una mirada regional y diferencial. El enfoque de la reparación no debe ser exclusivamente jurídico, ni centrarse simplemente en los marcos institucionales abiertos por la ley. La mirada debe ser territorial y las acciones deben construirse en contexto, con equipos mixtos, entre profesionales y gente de las comunidades que poseen el saber de lo local, para promover, fortalecer, generar y apoyar procesos que puedan tener una clara orientación desde abajo y, por tanto, reconstruir el tejido social desde el lugar donde se puede hacer con real eficacia, más allá de metas, indicadores y resultados: la comunidad, la vida cotidiana y el sentido construido por los sujetos colectivos e individuales de cada municipio en Colombia.

Por ello, en medio de un contexto como el colombiano, en el que la mayor parte de la población víctima tiene insatisfechas sus necesidades básicas, el Estado debe trazarse el complicado, pero necesario reto de trascender la reparación material, limitada a una indemnización no compensadora, que cuando, además, llega sin ninguna otra medida que la complemente, puede significar para las personas víctimas un paño de agua tibia o sólo una ayuda, que realmente no aporta a su proceso de recuperación ni a la reconstrucción del tejido social. Si bien, para las personas víctimas de diferentes naciones, incluida Colombia, la reparación material suele ser considerada como la más importante, lo que puede hallar fundamento en las condiciones de vulnerabilidad en las que estas generalmente se encuentran, en sus múltiples necesidades básicas insatisfechas y en las condiciones estructurales que obstaculizan la transición, la forma en que las indemnizaciones se están llevado a cabo han impactado negativamente en la identidad, formas de relación, escalas morales de las personas víctimas, generando procesos sociales y culturales que rompen con formas tradicionales de relación y con dinámicas, incluso económicas, que afectan la vida cotidiana del municipio y sus comunidades.

Acompañar estas acciones de la dimensión simbólica y el acompañamiento psicosocial, será siempre una labor compleja si se quiere partir de la vida, los significados y los contextos de la gente; puesto que requiere una transformación de la misma estructuración operativa del Estado. Además de lo anterior, en un contexto como el de San Carlos, con tierras codiciadas para diversos proyectos de desarrollo o explotación minera y de recursos naturales, son fundamentales medidas claras de no repetición que protejan el territorio y los proyectos de vida de sus habitantes. Pero además, verdaderas políticas con justicia social que permitan transformar su situación de exclusión y empobrecimiento históricos.

Por todo esto, podemos afirmar, tal como se expresó en el texto de Villa, Londoño \& Barrera $(2014,2015)$ que las condiciones sociopolíticas y culturales colombianas, y en el caso de San Carlos, están caracterizadas por la continuidad del conflicto armado, incluso cuando en esta año 2015 parece que se avanza hacia la recta final de la negociación política del final del conflicto armado entre el Estado y las FARC; pero donde se ha normalizado la violación de los derechos humanos, donde se operó la mutación de las estructuras armadas desmovilizadas de los grupos paramilitares, donde siguen dominando discursos contradictorios respecto a la transición y la subyacente confusión política y mental que estos generan, por la pervivencia de muchas de las personas víctimas en situaciones de vulnerabilidad e insatisfacción de sus necesidades básicas y por las pocas reformas institucionales. Todas estas condiciones dificultan la culminación de la cadena violenta que por años ha acaecido en el país y en el municipio de San Carlos; y por lo tanto hacen de las garantías de no repetición una realidad aún inalcanzable. Y en este contexto y con 
lo recogido en la presente investigación, la reparación dista mucho de ser un proceso que aporte a la reconstrucción del tejido social, a la paz y la reconciliación.

Al igual que el informe de la Mesa Nacional de Victimas de organizaciones Sociales, se ha ce un llamado a repensar los tiempos que establece la Ley 1448, en tanto que a la fecha, Junio de 2015, la reparación integral no ha sido tal, haciéndose necesario re-pensar y modificar el plazo de 6 años que aún faltan, según la Ley 1448, para dar por concluido el proceso de reparación, esto en tanto, no son suficientes para lograr una reparación integral real, del total de víctimas incluidas en el Registro Único de Víctimas (Ruv). 


\section{Referencias Bibliograficas}

Balvín Alvarez, J. B., Insuasty Rodriguez, A., Bastidas, W., Carrion, J., \& Pineda, J. E. (2010). Víctimas en contexto de violencia e mpunidad. Medellín. Medellín: Instituto Popular de Capacitación (IPC).

Barkan, E. (2000). The Guilt of Nations. New York : Norton.

Baró , M. (1990). Guerra y Salud Mental. En Psicología social de la guerra. San Salvador: UCA editores.

Baró, M. (1989). Sistema, grupo y poder. Psicología social desde Centroamérica II. San Salvador: UCA editores.

Bello, M. (2007). Bojayá: "La culpa de las víctimas y de los victimarios". Obtenido de psicosocial.net: http://www.psicosocial.net/grupo-accion-comunitaria/centro-dedocumentacion-gac/psiquiatria-psicologia-clinica-y-psicoterapia/manuales-y-textosbasicos /334-bojaya-la-culpa-de-las-victimas-y-los-victimarios/file

Bello, M., Martín, E., Millán, C., Pulido, B., \& Rojas, R. (2005). Bojayá, Memoria y Río. Violencia Politica, Daño y Reparación. Bogotá: Editorial UNIBIBLOS, Colciencias y Universidad Nacional de Colombia, programa de iniciativas universitarias para la Paz y la Convivencia (PIUPC) Facultad de Ciencias Humanas, Departamento de Trabajo Social.

Beristain, C. (1999). Reconstruir el tejido social. Barcelona: ICAIRA.

Beristain, C. (2008). "Memoria colectiva y reconstrucción de sociedades fracturadas por la violencia". En "Verdad, memoria y reconstrucción: Estudios de caso y análisis comparado". Bogotá: Centro Internacional de Justicia Transicional ICTJ.

Beristain, C. (2009). Diálogos sobre la reparación: que reparar en los casos de violaciones de derechos humanos. Quito: Ministerio de Justicia y Derechos Humanos.

Beristain, C. (2010). El derecho a la reparación en los conflictos socioambientales. Bilbao: Hegoa y Universidad del país Vasco.

Beristain, C. (2010). Manual sobre perspectiva psicosocial en la investigación de derechos humanos. Bilbao: Universidad del Paîs Vasco y Hegoa.

Beristain, C., \& Pérez Sales, P. (2008). Trauma, development and peace building: a Latin American perspective. Reino Unido: Incore-IDRC, University of Ulster Belfast.

Beristain, C., \& Riera, F. (1994). "Afirmación y Resistencia. La comunidad como apoyo". Barcelona: Virus Editorial.

Centro de Memoria Histórica CMH. (2011). San Carlos: Memorias del éxodo de la guerra. Bogotá: Editorial Taurus.

Flick, U. (2004). Introducción a la investigación cualitativa. . Madrid y A Coruña: Ediciones Morata y Fundación Paideia.

Gómez Isa, F. (2006). El derecho de las víctimas a la reparación por violaciones graves y 
sistemáticas a los derechos humanos. En F. Gómez Isa, El derecho a la memoria, Giza Eskubideak- Derechos Humanos. Bilbao: Alberdania.

Gónzalez Chavarria, A. (2010). Justicia transicional y reparación a las víctimas en Colombia. Revista Mexicana de Sociología, 72(4), 629-658.

González, F., Bolivar, I., \& Vásquez, T. (2002). Violencia politica en Colombia. De la nación fragmentada a la construcción del Estado. Bogotá: CINEP.

Hamber, B. (2000). Repairing the irreparable: Dealing with the double-binds of making reparations for crimes of the past. Ethnicity and Health, 5(3/4), 215-226.

Insuasty Rodriguez, A., Jesús William, B. A., \& Cadavid Acevedo, P. (2009). Victimas, Violencia y despojo. Medellín: Litoimpacto.

Jaramillo , P. (2012). Deuda, desesperación y reparaciones inconclusas en la Guajira, Colombia. Bogotá: Antípoda.

Jaramillo Marín, J. (2010). Narrando el dolor y luchando contra el olvido en Colombia. Recuperación y trámite institucional de las heridas de la guerra. Revista Sociedad y Economia, 205-228.

Jaramillo Marin, J. (2010). Reflexiones sobre los usos y abuso de la verdad, la justicia y la reparación, en el proceso de justicia y paz colombiano (2005-2010). Ciencia politica, 15(1), 13-46.

Mack, H. (2007). Justicia transicional en Guatemala: la confrontación política y la crisis de gobernabilidad diluyen las opciones de examinar el pasado. En Serie enfrentando el pasado. El legado de la verdad: impacto de la justicia transicional en la construcción de democracia en América Latina. Bogotá: ICTJ.

Marin Ortiz, I., \& Gaviria Betancur, P. (2010). Elementos para una politica de verdad, justicia y reparación integral para las víctimas. Bogotá: Fundación Social.

Mesa Nacional de Victimas conformada por organizaciones sociales. (13 de Junio de 2015). Avances Y Retrocesos: Ley De Victimas Y Restitución De Tierras. Obtenido de Kavilando. org: $\quad$ http://kavilando.org/index.php/2013-10-13-19-52-10/conflicto-social-ypaz/3650-avances-y-retrocesos-ley-de-victimas-y-restitucion-de-tierras

Olaya, C. (2012). Nunca más contra nadie. Ciclos de violencia en la historia de San Carlos, un pueblo devastado por la guerra. . Medellin: Cuervo Editores.

Olaya, C. (2015). La violencia sociopolítica y sus impactos en el municipio de San Carlos, Oriente de Antioquia. Revista Kavilando, 6(2).

Pécaut, D. (2001). Guerra contra la sociedad. Bogotá: Editorial Planeta Colombia.

Pécaut, D. (2003). Violencia y politica en Colombia. Elementos de reflexión. Medellín: Hombre Nuevo Editores. 
Rebolledo, O., \& Rondón , L. (2010). Reflexiones y aproximaciones al trabajo psicosocial con víctimas individuales y colectivas en el marco del proceso de reparación. Revista de Estudios Sociales, 40-50.

Sikkink, K., Marchesi, B., Dixon, P., \& D` Alessandra, F. (24 de Octubre de 2014). Reparaciones integrales en Colombia: logros y desafios. Evaluación comparativa y global. Obtenido de static.iris.net: http://webcache.googleusercontent.com/ search?q=cache:sqz-gxTcPQ4J:static.iris.net.co/semana/upload/documents / Documento_409315_20141116.pdf+\&cd=1\&hl=es-419\&ct=clnk\&gl=co

Unidad de Atención y Reparación Integral a las Víctimas UARIV. (2014). Informe de gestión 2011-2014 en el municipio de San Carlos. Bogotá: Comunicación interna de subdirectora de la entidad.

Uprimny Yepes, R., \& Guzmán Rodríguez, D. (2010). En búsqueda de un concepto transformador y participativo para las reparaciones en contextos transicionales. Revista Colombiana de Derecho Internacional, 231-286.

Utas, M. (2005). Victimicy, girlfriend, "soldiering: tactic agency in a young woman's social navigation of the Liberian war zone. Antropological Quartely, 78(2), 403-440.

Verdad Abierta. (21 de Diciembre de 2014). Verdad Abierta. Obtenido de verdadabierta.com: http:/ / www.verdadabierta.com/lucha-por-la-tierra/5558-debates-de-la-restitucion-detierras-en-2014

Viaene, L. (2008). Justicia Transicional y Contexto Cultural en Guatemala: Voces Q`eqchiès sobre el Programa Nacional de Reparaciones. En La vida NO tiene precio: acciones y omisiones del Resarcimiento en Guatemala. Guatemala: Magna Terra Editores.

Villa, J. ( Octubre del 2014). Un análisis crítico a la intervención psicosocial con víctimas del conflicto armado en Colombia. . IX Cátedra Internacional Martín Baró. Bogotá: Universidad Pontificia Javeriana.

Villa, J. (2013). Consecuencias Psicosociales de la participación en escenarios de justicia transicional en un contexto de conflicto, impunidad y no-transición. El Ágora USB, 13(2), 307-338.

Villa, J. (2014). Recordar para reconstruir: El papel de la memoria colectiva en la reconstrucción del tejido social, el empoderamiento colectivo, la recuperación de la dignidad y la transformación subjetiva de las víctimas del conflicto armado en tres regiones de Colombia. Medellin: Editorial Bonaventuriana.

Villa, J., Londoño, D., \& Barrera, D. (2014). Reparación a las víctimas de dictaduras, conflictos armados y violencia política. Parte I. El Ágora USB, 14(2), 339-376.

Villa, J., Londoño, D., \& Barrera, D. (2015). Reparación a las víctimas de distaduras, conflictos armados y violencia política en sus componentes de compensación, satisfacción, rehabilitación y no repetición. El Ágora USB, 15(1), 217-240. 
Yzerbyt, V., \& Demoulin, S. (2010). Intergroup relations. En S. Fiske, D. Gibert, \& G. Lindzey, Handbook of social psychology (5th edition ed., págs. 1024-1083). Hoboken, NJ: Wiley.

Nota.

\footnotetext{
${ }^{3}$ El presente artículo hace parte del proceso de investigación "Construcción de significados sobre la reparación institucional y la reparación desde abajo en víctimas del conflicto armado en el municipio de San Carlos". Después de presentar un estado de la cuestión sobre el tema de reparación, publicados en los dos números anteriores de "El Ágora USB", el equipo de investigación presenta en este texto algunos de los resultados obtenidos en el trabajo de campo, en el cual, se desarrolló un seguimiento significativo, desde la perspectiva de la población, a las acciones que el Estado Colombiano, en los diversos momentos entre 2008 - 2014, ha realizado en pro de la reparación de las víctimas en esta localidad. El trabajo se desarrolló a través de una investigación cualitativa con el objetivo de recoger de viva voz la experiencia de los y las participantes a través de 12 grupos focales, con la participación de 150 personas, 7 entrevistas individuales y 5 entrevistas grupales para completar un número de 170 personas participantes. Los resultados recogen los relatos de los y las participantes en torno a los procesos de indemnización, ayuda humanitaria, retornos y restitución, medidas contempladas en la ley 1448 de 2011 para la atención y reparación a víctimas del conflicto armado.
} 
